an astronomical conference held in Moscow in September last. A great astrophysical observatory is to be established with headquarters at Simferopol in the Crimea. There will be three observing stations, one in the Crimea at an altitude of 2,000 metres, a solar station at an altitude of 3,500 metres, and a station somewhere in the southern hemisphere. The equipment will include a 120 -in. reflector, two 80 -in. reflectors, two 16-in. double astrographs, one 50-in. and one 30-in. Schmidt telescope, solar towers and a coronagraph. The training of astronomical staff has continued during the War; some sixty or seventy astronomers and astrophysicists will be required for staffing the new institution. Information has been received that the international latitude station maintained by the U.S.S.R. at Kitab, Uzbekistan, has continued to function regularly throughout the War.

\section{Library Service in South Africa}

IN his presidential address to Section $\mathbf{F}$ of the South African Association for the Advancement of Science delivered on June 29, 1943, on "Libraries and Science" (South African J. Sci., 40, 81 ; November 1943), P. Freer referred particularly to the difficulties of book selection in scientific literature. He urged that this is not a matter for librarians alone, and that librarians should also do more to secure the writing and publishing of authoritative but simple and readable books on important subjects. After pleading for more care and co-operation in the discarding of surplus or unwanted stock, Mr. Freer indicates measures that are required for the full efficiency of the inter-library loan system. Until the master-catalogue of non-fiction in the libraries of the Union of South Africa is completed, as well as the publication of a new edition of the Lloyd's List of Scientific and Technical Periodicals, with a complementary volume covering the humanities, book-buying and discarding are both unscientific. As regards the imperfections and limitations of present abstracting and indexing services for scientific and technical periodicals, Mr. Freer notes that only forty-one of the three hundred abstracting and indexing periodicals in existence in 1937 were available somewhere in South Africa, and these periodicals only covered one third of the scientific papers concerned. $\mathrm{He}$ emphasized the need, for the advancement of science, of a highly trained staff and augmented resources to diminish the gap between the 6,000 titles in the Catalogue of Union Periodicals and the 15,000 acknowledged as being of international importance. Plans for postwar reconstruction contained no suggestions for a national library system, but in addition to national libraries, regional libraries and organization would be required. Finally, he referred to the contribution which science could make to the improvement of the printed book itself and its preservation.

\section{Mexican Institute of Nutrition}

Accordng to an annotation in the September issue of the Boletin de la Oficina Sanitaria Panamericana, the newly organized Institute of Nutrition in Mexico includes the following sections : bromatology, economic, social and dietetic departments, clinical medicine and a clinical laboratory, and maternal and child welfare. In the near future, the bromatology section will undertake studies of the chemical composition of legumes and maize, and the economic section will undertake an investigation of the state of nutrition of about seven hundred families in an area of
Mexico City. The elinical laboratory will determine the vitamin content and blood count of the families studied. The maternal and child welfare division has already started work on the vitamin content of the blood of pregnant women at different periods of pregnancy, and a training centre has made plans for courses for the selection of dietitians and experts in nutrition.

\section{An Automatic Vibration Analyser}

ONE of the potential causes of failures in an aeroplane power-plant or the aeroplane structure itself is excessive vibration. While every effort is made to reduce the number of modes of vibration which might be excited to objectionable amplitudes, it is desirable to measure the power-plant and aeroplane vibration characteristics in flight to ensure that there are no vibrations of sufficient magnitude to cause fatigue failures in any parts. In the Bell Laboratories an automatically tuned wave analyser has been developed to meet the needs of the Pratt and Whitney Aircraft Division of United Aircraft Corporation, which desired apparatus that when used in conjunction with suitable vibration pickups would measure the amplitude of vibration at a frequency equal to any predetermined multiple of engine revolution per minute, even when the engine speed is continuously changed. This analyser can be used with a recorder to draw curves of the amplitude of vibration of selected orders of frequency as a function of engine speed. An article by F. G. Marble (Bell Lab. Rec., 22, No. 8; April 1944) describes the analyser and its use.

\section{Illuminating Engineering Society}

DURING the past few years the membership of the Illuminating Engineering Society has approximately doubled, it has formed new centres and groups throughout Great Britain, and its activities have greatly increased. In addition, it has in prospect a programme of still greater activity and of new developments in the post-war period. In order to cope with these developments the Council is now contemplating the appointment of a full-time paid secretary who, it is hoped, will eventually take full charge of its administration. In the meantime, however, the Council hopes to continue to benefit for sone time to come from the services of its honorary secretary, Mr. J. S. Dow, who has been associated with the Society since its inception in 1909.

\section{Institution of Electrical Engineers : Radio Section}

ON the recommendation of the Wireless Section Committee the Council of the Institution of Electrical Engineers has decided to change the name of the Section to "Radio Section" and to modify Rule No. 1, which deals with the scope of the Section, to read as follows: "The Section shall include within its scope all matters relating to the study, design, manufacture or operation of apparatus for communication by wave radiation, for high-frequency and electronic engineering, or for the electrical recording or electrical reproduction of sound".

ERrata.-In the communication "Physico-Chem. ical Properties of the Surface of Growing Plant Cells" by Prof. H. Lundegardh and G. Stenlid in Nature of May 20, p. 618, Fig. 1 and Fig. 2 should be interchanged. The absorption maximum of the flavonone is in two places in the text erroneously assigned to $2550 \mathrm{~A}$. instead of $2850 \mathrm{~A}$. 